This item was submitted to Loughborough's Research Repository by the author.

Items in Figshare are protected by copyright, with all rights reserved, unless otherwise indicated.

\title{
Preferential transport of microplastics by wind
}

PLEASE CITE THE PUBLISHED VERSION

https://doi.org/10.1016/j.atmosenv.2020.118038

PUBLISHER

Elsevier

VERSION

AM (Accepted Manuscript)

PUBLISHER STATEMENT

This paper was accepted for publication in the journal Atmospheric Environment and the definitive published version is available at https://doi.org/10.1016/j.atmosenv.2020.118038.

\section{LICENCE}

CC BY-NC-ND 4.0

\section{REPOSITORY RECORD}

Bullard, Joanna, Annie Ockelford, Patrick O'Brien, and Cheryl McKenna Neuman. 2020. "Preferential Transport of Microplastics by Wind”. Loughborough University. https://hdl.handle.net/2134/13148378.v1. 
3 Authors: *Joanna E. Bullard ${ }^{1}$, Annie Ockelford ${ }^{2}$, Patrick O’Brien ${ }^{3}$, Cheryl McKenna

Neuman ${ }^{3}$

\section{Affiliations:}

$6{ }^{1}$ Geography and Environment, Loughborough University, Leicestershire LE11 3TU UK.

$7{ }^{2}$ School of Environment and Technology, University of Brighton, Brighton, BN2 4GJ

8 UK.

$9{ }^{3}$ Trent Environmental Wind Tunnel Laboratory, School of the Environment, 1600 West

10 Bank Drive, Trent University, Peterborough, Ontario, Canada K9J 0G2.

$12{ }^{*}$ Correspondence to: j.e.bullard@lboro.ac.uk. 


\section{Abstract}

17 Contamination of terrestrial and marine environments by plastic waste has been widely documented. Most research into the distribution of microplastics has focused on water but here we show that wind transport can be very effective in mobilising microplastic particles. A series of wind tunnel experiments using two different substrates (sand and soil), two different microplastics (microbeads and fibres) and 5 different concentrations of microplastics (ranging from $0 \mathrm{mg} \mathrm{kg}^{-1} \mathrm{dw}$ to $1040 \mathrm{mg} \mathrm{kg}^{-1} \mathrm{dw}$ ) is used to demonstrate that microplastics are preferentially transported by wind compared to sand and soil. When compared to either of the untreated substrate beds $\left(0 \mathrm{mg} \mathrm{kg}^{-1} \mathrm{dw}\right)$, the inclusion of microplastics was not found to significantly affect the wind erosion threshold for any of the concentrations or geometric forms (fibres or beads) tested. Averaged over all concentrations of microplastics and both substrate types, microplastic enrichment was lower for microbeads than fibres. The enrichment of microplastic fibres within the entrained particulate matter was one to two orders of magnitude higher for both test bed substrates, ranging from 98 to 498 for the sand and 278 to 726 for the soil. This suggests

31 microplastic shape needs to be carefully parameterized in models of atmospheric 32 microplastic transport. We suggest that microplastic research could benefit from previous 33 investigations into the wind erosion of soil organic carbon. 


\section{Keywords}

38 Wind erosion

39 Microplastic entrainment

40 Particle shape

41 Microbead

42 Fibre

43 Plastic cycle

44

45 Highlights

46 - We ran experiments to determine the susceptibility of microplastics to wind erosion

- Fibrous microplastics are preferentially transported compared to microbeads

- Particle shape may affect the atmospheric transport distance for microplastics 
53 Plastics are highly versatile, low-cost, lightweight, materials and hence in high societal 54 demand for innovation-driven growth and development (North and Halden, 2013; PlasticsEurope, 2019). The properties that make plastics useful - strength, flexibility, durability - also make them difficult to dispose of, and their resistance to degradation has introduced persistent, complex materials to the environment that may have serious consequences for environmental pollution (e.g. Andrady, 2011; Barnes et al., 2009; Free et al., 2014; Jambeck et al., 2015), environmental health (e.g. Gasperi et al., 2018; He, D. et al., 2018; Wright and Kelly, 2017) and ecosystem functionality (e.g. Hu et al., 2019; Lwanga et al., 2016; Arias-Andres et al., 2018). This paper focuses on microplastics, defined as solid synthetic-polymer-containing particles less than $5 \mathrm{~mm}$ in size (NOAA/European Marine Strategy Directive). Microplastics can be purposefully produced to be small in size (primary microplastics) or derived from the breakdown of macroplastics (to form secondary microplastics) by chemical (Mailhot et al., 2000; Song et al., 2017), microbial (Yuan et al., 2020) and mechanical processes (Song et al., 2017).

Breakdown of plastics since the onset of mass production 70 years ago has resulted in a decrease in the average size of plastic particles and an increase in the abundance and distribution of secondary microplastics, which are pervasive and difficult to remove from the environment (Barnes et al., 2009).

Microplastics have potentially deleterious effects on terrestrial, freshwater and marine environments (e.g. recent reviews by Beaumont et al. 2019; Wang et al., 2020; Li et al., 2020). Research into their long-term effects is in its infancy, but the risks may include damage to organisms' digestive systems (von Moos et al., 2012; Tanaka \& Takada, 2016; Wright et al., 2013), facilitating the transfer of harmful chemicals, including persistent 
2018), and alterations to soil stability (Boots et al., 2019; Barnes et al., 2009; Lehmann et al., 2019; Zhang et al., 2019; Machado et al., 2018).

Microplastics derive from land-based anthropogenic activity with $>50 \%$ of all microplastics estimated to be retained in the terrestrial environment (Boucher and Friot, 2017; Zalasiewicz et al., 2016). Despite this, most scientific and media attention has focused on microplastics in the marine depositional sink and presence/absence in the terrestrial environment. The main focus for research in to microplastic transport pathways has been via rivers to the oceans, however recent studies of soils (Scheurer and Bigalke 2018; Allen et al., 2019; Rezaei et al., 2019), snow (Bergmann et al., 2019), supraglacial debris (Ambrosini et al., 2019) and total atmospheric fallout (Dris et al., 2016) indicate airborne transport may be important. The wind erosion and transport of microplastic can not only redistribute particles within the terrestrial environment but atmospheric fallout is also likely to contribute to marine pollution (Evangeliou et al., 2020).

A recent review of atmospheric microplastics (Zhang et al., 2020) highlights that most research has focused on atmospheric deposition of plastic particles. In particular, studies of atmospheric deposition have focused on cities in China (e.g. Cai et al., 2017; Liu et al., 2019; Zhou et al., 2017), France (Dris et al., 2015, 2016, 2017), Germany (Klein and Fischer et al., 2019), Iran (Dehghani et al., 2017; Abbasi et al., 2019) and the UK (Stanton et al., 2019; Wright et al., 2020), where outdoor microplastic abundance ranges from <5 to $>1000$ particles $\mathrm{m}^{-2} \mathrm{~d}^{-1}$, or $2->9000 \mathrm{mg} \mathrm{kg}^{-1}$. Studies of rural and remote environments have identified microplastics in snow in the Pyrenees mountains (Allen et al., 2019), Alps (Ambrosini et al., 2019) and Arctic (Bergmann et al., 2010) and in remote lake catchments in Ireland (Roblin and Aherne, 2020). Microplastics have also been found in floodplain 
soils in nature reserves in Switzerland (Scheurer and Bigalke, 2018). The distance of

104 these rural or remote locations from urban areas suggest that airborne, rather than fluvial, transport is a more likely source of at least a proportion of the microplastics found there.

Microplastics take a variety of forms including fragments (flattened, angular), fibres (eventhickness, linear, flexible), films (thin and typically transparent), foams (compressible, sponge-like texture) and beads (granular, rounded). The shape depends both on the

110 specific type of plastic, the original form of the primary plastic, the processes operating to 111 degrade macroplastics to microplastics, age and environmental residence time. For example, fibres are often associated with shedding from textiles, beads with personal care products, foams with insulation or food packaging, and fragments as by-products of

114 manufacturing or the breakdown of macroplastics (Rochman et al., 2019). The most 115 common shapes identified for atmospheric microplastics are fibres e.g. $>90 \%$ in Paris 116 (Dris et al., 2015); >80\% in Dongguan (Cai et al., 2017); 95\% in Yantai (Zhou et al., 117 2017),China; and 92\% in London (Wright et al., 2020): or fragments e.g. >90\% in 118 Hamburg (Klein and Fischer, 2019) and 68\% in the Pyrenees (Allen et al., 2019). This is

119 likely to reflect a combination of the prevalence of shapes at nearby sources (e.g. urban 120 areas that are production centres for synthetic fibres) and the influence of shape on 121 atmospheric transport and residence time.

123 The small size and often low density of microplastics means that when they are exposed 124 to wind erosion they are likely to be very susceptible to entrainment and transport. This 125 may mean microplastics form a potential risk to human (Gasperi et al., 2018) and 126 ecosystem health in locations far-removed from their origin (Rezaei et al., 2019). To date 
127 there have been very few studies of the entrainment potential of microplastics by wind

128 nor of the impact of particle properties on the mode and distance of airborne transport

129 (Waldschläger et al., 2020). Rezaei et al., (2019) used a field wind tunnel study to

130 demonstrate that wind-eroded sediments from both agricultural and natural areas were

131 enriched with microplastics compared to the original soils but there is no indication of

132 whether particular forms (shapes) of microplastics are preferentially eroded.

134 The aim of this paper is to explore the extent to which microplastic particles are preferentially-transported compared to natural sediments using a series of controlled wind tunnel experiments. Two different substrates (sand and soil) and two different shapes of

137 microplastic (bead and fibre) were used to determine the impact of substrate and shape 138 on microplastic entrainment.

\section{Materials and Methods}

\section{$141 \quad 2.1$ Materials}

142 Experiments were performed in the Trent University Environmental Wind Tunnel (TEWT),

143 a boundary layer simulation tunnel with an open-loop suction design. The tunnel working

144 section is $12.5 \mathrm{~m}$ long, with a cross section $0.7 \mathrm{~m}$ wide by 0.76 high, and the whole tunnel

145 is housed in an environmental chamber which, for this study, was held constant at $20^{\circ} \mathrm{C}$ 146 and $20 \%$ relative humidity to control electrostatics. Further details of the TEWT facility 147 are provided in previous publications (Nickling and McKenna Neuman 1997; McKenna

148 Neuman and Nickling, 2000; Li and McKenna Neuman, 2012).

150 Experiments were conducted using two substrates and two types of microplastic. With a 151 particle density of $2.65 \mathrm{~g} \mathrm{~cm}^{3}$, substrate one was well-sorted quartz sand (hereafter 
152 'sand') similar to that found on beaches (Constant et al., 2019) and lakeshores (Zhang et

153 al., 2016) from which high concentrations of macro- and microplastics have been reported

154 (Fig. 1a; Table 1). Substrate two was a poorly-sorted soil containing $13.2 \%$ organic matter

155 (calculated by loss on ignition at $850^{\circ} \mathrm{C}$ ) (hereafter 'soil') (Fig.1b; Table 2). Both

156 substrates were air-dried and stored in the same environmental chamber that houses the

157 wind tunnel. The sand is likely to have similar erodibility to dry, loose in situ sand e.g. on

158 dry beaches or dunes, because it is well-sorted and, in the absence of organic crusting,

159 not subject to aggregation in the field. The soil may be less-representative of in situ field

160 conditions as the degree of aggregation and sorting may have been changed during the

161 preparation process, however the soil experiments are comparable with each other in

162 relative terms. The microplastics were (i) fluorescent, red, polyethylene microspheres in

163 the size range 212-250 $\mu \mathrm{m}$ with a density of $1.2 \mathrm{~g} \mathrm{~cm}^{3}$ (hereafter 'microbeads'), and

164 chosen to be similar in size/shape, but lower in density to the sand bed; and (ii) $5 \mathrm{~mm}$

165 long polyester fibres (hereafter 'fibres') having a width of $0.5-1 \mathrm{~mm}$ and a density of 1.38

$166 \mathrm{~g} \mathrm{~cm}^{3}$. Plastics were mixed with the substrate at concentrations of 40, 240, 640 and 1040

$167 \mathrm{mg} \mathrm{kg}^{-1} \mathrm{dw}$. For the microbeads, the associated range in particle count per $\mathrm{kg}$ is from 6200

168 to 160,000 (particle count for fibres could not be calculated). The lower concentrations

169 are comparable with field measurements (Scheurer and Bigalke, 2018; Zhang et al.,

170 2016) and predicted (Amec Foster Wheeler Environment \& Infrastructure, 2017)

171 environmental concentrations for agricultural soils, whilst the highest is at the lower end

172 of that reported for industrial areas (Fuller and Gautam, 2016).

173

174

175

176 

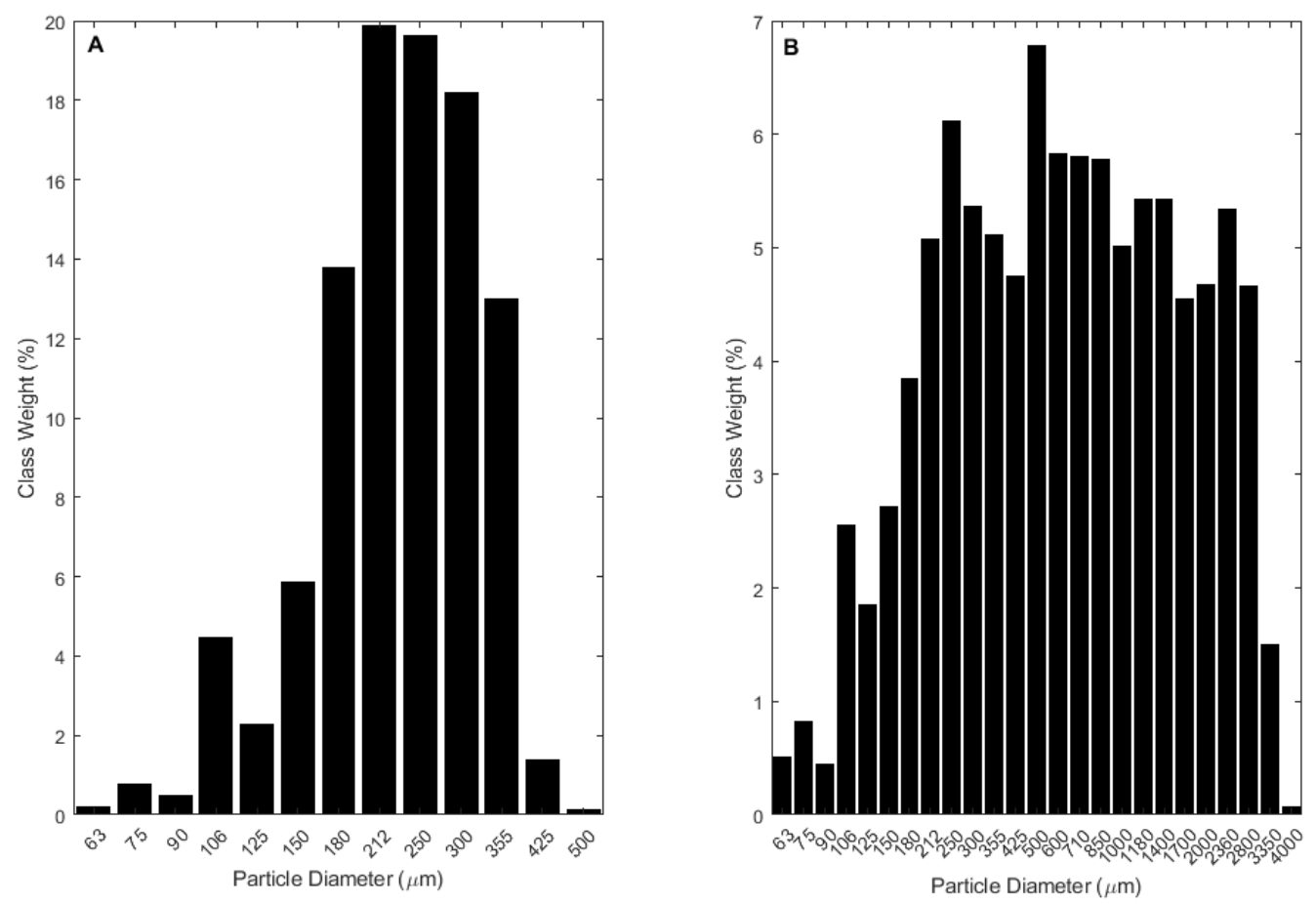

$178<$ Figure 1: (A) Particle size distribution of substrate one (sand) and (B) substrate 2 179 (soil). >>

\subsection{Methods}

For each experiment, test surfaces were prepared by filling a $0.025 \mathrm{~m}$ by $0.35 \mathrm{~m}$ by 1.0

$184 \mathrm{~m}$ metal tray with the given mixture of test material (substrate, or substrate + microplastic),

185 which was prepared by weighing and manually mixing the appropriate ratios of substrate

186 to plastic (Table 3 ). The test material was levelled such that the substrate surface was

187 level with the tunnel floor and finally an airtight seal was secured around the tray

188 perimeter. The upwind fetch was $8 \mathrm{~m}$, wherein the flow travelled over a loose bed of

189 randomly distributed gravel to adjust and achieve the desired aerodynamic roughness

190 upon reaching the test bed. 
192 For each threshold experiment, the freestream wind speed was increased from well below

193 threshold up to $14 \mathrm{~m} \mathrm{~s}^{-1}$ in $0.25 \mathrm{~m} \mathrm{~s}^{-1}$ increments to determine wind speeds for the 194 inception of intermittent and continuous saltation (Davidson-Arnott and Bauer, 2009); i.e. 195 particles moving across the bed surface in low ballistic trajectories. The freestream wind 196 velocity was sampled throughout the experiments at an elevation of $0.35 \mathrm{~m}$ using a micro

197 pitot tube positioned $1.42 \mathrm{~m}$ upwind of the test bed. Freestream wind speed was 198 controlled by a stepper motor with each "step" lasting 30 seconds with this stepping wind 199 speed pattern being typical of emissions threshold testing for dust and soils 200 (Ogungbemide, 2017). Experiments were performed in triplicate for each test material 201 (ratio of substrate to plastic). Vertical velocity profiles were collected at each wind speed 202 step and used to calculate the aerodynamic roughness and friction velocity by fitting the 203 velocity data to the Law of the Wall equation.

Particle transport was approximated by particle counts which were measured using two fork-type Wenglor ${ }^{\mathrm{TM}}$ gate sensors secured to the bed $2 \mathrm{~cm}$ downwind of the test surface. These sensors were attached equidistant from the walls of the tunnel, and particle counts were measured approximately $0.5 \mathrm{~cm}$ above the surface. Due to natural variability in the streamwise distribution of particle transport, data from both Wenglors were summed during analysis.

212 Trapped samples of mobilised material were retrieved after each run at distances of 5 , $21330,60,100,150$ and $200 \mathrm{~cm}$ downwind of the test bed using glycerol-coated microscope 214 slides attached to the wind tunnel base. The trapped samples were used to determine 215 microplastic enrichment ratios (Sharpley, 1985) - the ratio of microplastic content in the 216 particulate matter transported by creep and saltation to that in the original substrate. 
217 Published relationships between saltation and suspension are expected to provide insight

218 into long distance microplastic transport potential.

\subsection{Quantification of Microplastic Entrainment}

Although each wind tunnel experiment was repeated three times, quantities of entrained sediment and microplastics were small and therefore the material captured on the glycerol-coated slides was bulked together for replicate tests. Particles trapped on the slides were transferred onto cross hatched filter papers and distributed to ensure that samples were only one grain thick. Where large amounts of sediment were transported, multiple filter papers were used to ensure a single thickness of grains. Averages were taken of the derived data if more than one filter paper was needed per sample. Images of the filter papers were captured using a Leica S9D stereomicroscope microscope. The images were imported into ImageJ, a free image processing and analysis software package. The version used in this work was ImageJ 1.8.0_172 with the extension plugin Threshold Colour.

For each image a central sub region was cropped and the scale applied such that images were scaled to their actual size. The total area of the image covered by sediment was calculated using the Threshold Colour plug-in. This plugin can threshold a specific colour from an image by selecting a range of values within the HSB (Hue, Saturation, Brightness)

237 range. Given photographs of the samples were taken under constant light conditions, 238 once the HSB value was derived for the first image it was kept constant for all subsequent analysis. Following this thresholding procedure, a binary transformation was applied to separate the selected colour from all other pixels. The surface area of the thresholded 241 pixels was then automatically calculated using ImageJ. 
243 In addition to the total area covered by sediment in each image, the total number of

244 microplastic particles was manually counted. The microplastic spheres were of a known 245 calibrated diameter of $212 \mu \mathrm{m}$ so once the total number per image was known the total

246 area they occupied could be calculated. A greater range in sizes was observed for the

247 fibres so for each image alongside the total number of fibres, the length, width and total 248 area of individual fibres was also measured. For all fibres analysed the median area was

$2493.8 \mathrm{~mm}^{2}$, mean area was $4.35 \mathrm{~mm}^{2}$ and the standard deviation of the area was $4.36 \mathrm{~mm}^{2}$.

250 In the results presented herein the median area was multiplied by the number of fibres to 251 give the total area per image.

$254 \quad 3 . \quad$ Results

\section{$255 \quad 3.1 \quad$ Velocity-flux profiles}

256 For the test beds without microplastics, the threshold for intermittent saltation was 7.25$7.5 \mathrm{~m} \mathrm{~s}^{-1}$ for sand and $11-12 \mathrm{~m} \mathrm{~s}^{-1}$ for soil (Table 4). The threshold for continuous saltation was higher in each case at 7.5-8 $\mathrm{m} \mathrm{s}^{-1}$ for sand and $12.5-13.5 \mathrm{~m} \mathrm{~s}^{-1}$ for soil. Mineral particles and microplastics were entrained and transported during all the experiments.

260 For the sand and soil test beds including microplastics intermittent saltation occurred in 261 the range 6.75 to $7.5 \mathrm{~m} \mathrm{~s}^{-1}$ and 10.0 to $13.5 \mathrm{~m} \mathrm{~s}^{-1}$, respectively, as compared to the higher

262 wind speeds required for continuous saltation which were 7.5 to $8 \mathrm{~m} \mathrm{~s}^{-1}$ (sand) and 11.5 263 to $14 \mathrm{~m} \mathrm{~s}^{-1}$ (soil)(Table 4). When compared to either of the untreated test beds, the 264 inclusion of microplastics was not found to significantly affect the wind erosion threshold 265 (continuous or intermittent) for any of the concentrations or geometric forms (fibres or 266 beads) tested (Table 4). 
268 The velocity-flux profiles for Run 1 of each experiment are shown in Figure 2. For the

269 sand beds the similarity of threshold is evident but there are differences in the relationship

270 between total particle count (mineral particle + microplastic) and wind velocity. Above

271 threshold for a given wind speed the flux over the sand bed is higher for experiments

272 including microplastics than for sand without microplastics, and higher where the

273 microplastics are fibres than for experiments including beads. For example, for a wind

274 speed of $7.75 \mathrm{~m} \mathrm{~s}^{-1}$ the flux is 7.6 counts $\mathrm{cm}^{-1} \mathrm{~s}^{-1}$ for the pure sand bed, $18-16.5$ counts $275 \mathrm{~cm}^{-1} \mathrm{~s}^{-1}$ for the sand bed including microplastics, and 11-31.5 counts $\mathrm{cm}^{-1} \mathrm{~s}^{-1}$ for the sand

276 bed including fibres. Experiments using the soil bed are less systematically variable. At

277 low wind speeds the flux fluctuates but following the onset of continuous saltation the soil

278 beds including fibres generally have a higher flux than those containing beads for the

279 same wind speed. One exception is the run with the lowest concentration of fibres (40

$280 \mathrm{mg} \mathrm{kg}^{-1} \mathrm{dw}$ ), where flux is lower for beds including microplastics than for the soil bed with 281 no microplastics added. 

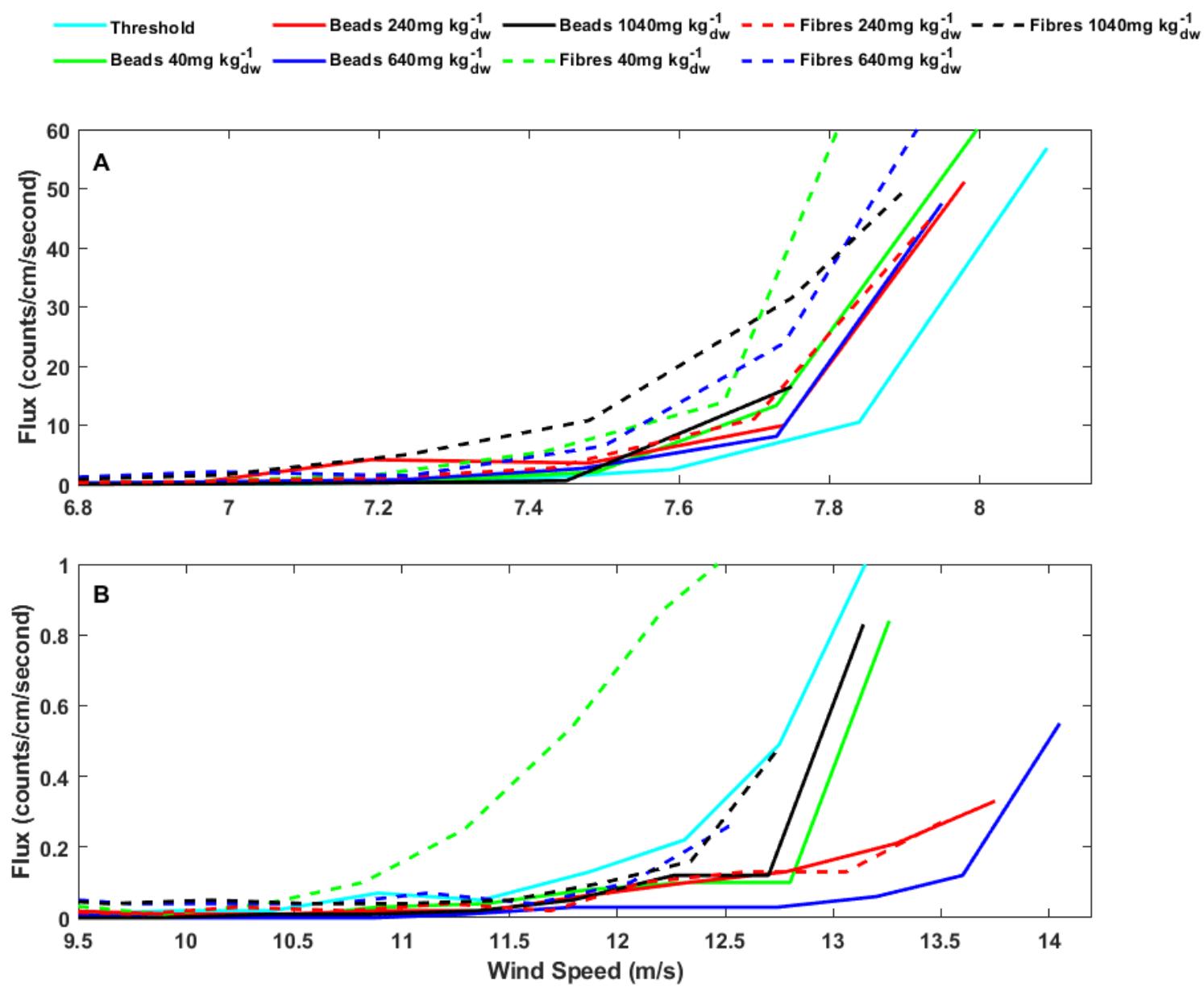

284 < Figure 2: Relationship between wind speed and flux (mineral particle + microplastics)

285 for A) sand bed, and B) soil bed. >>

\subsection{Microplastic Enrichment Ratios}

289 The susceptibility of microplastic particles to wind entrainment was determined by

290 calculating the ratio of microplastic content in the transported material to that in the

291 original substrate. The mean number of microplastic particles transported in each

292 experiment ranged from 11 to 78 for the microbeads and 3 to 191 for fibres. Averaged

293 over replicates of all concentrations of microplastics, distances and both substrate types,

294 microplastic enrichment was lower for microbeads than fibres (Figure 3; Table 3). For

295 the soil tests, the enrichment ratio for microbead entrainment was lowest and close to 1 
296 for most concentrations. This suggests the relative quantity of microbeads transported is

297 similar to that for natural particles in the soil population. Enrichment ratios for microbeads 298 entrained from sands ranged from 5.03 for the lowest concentration to 3.12 for the highest

299 concentration. Notably, the enrichment of microplastic fibres within the entrained 300 particulate matter was one to two orders of magnitude higher for both test bed substrates, 301 ranging from 98.15 to 498.25 for the sand and 278.14 to 726 for the soil (Table 3).

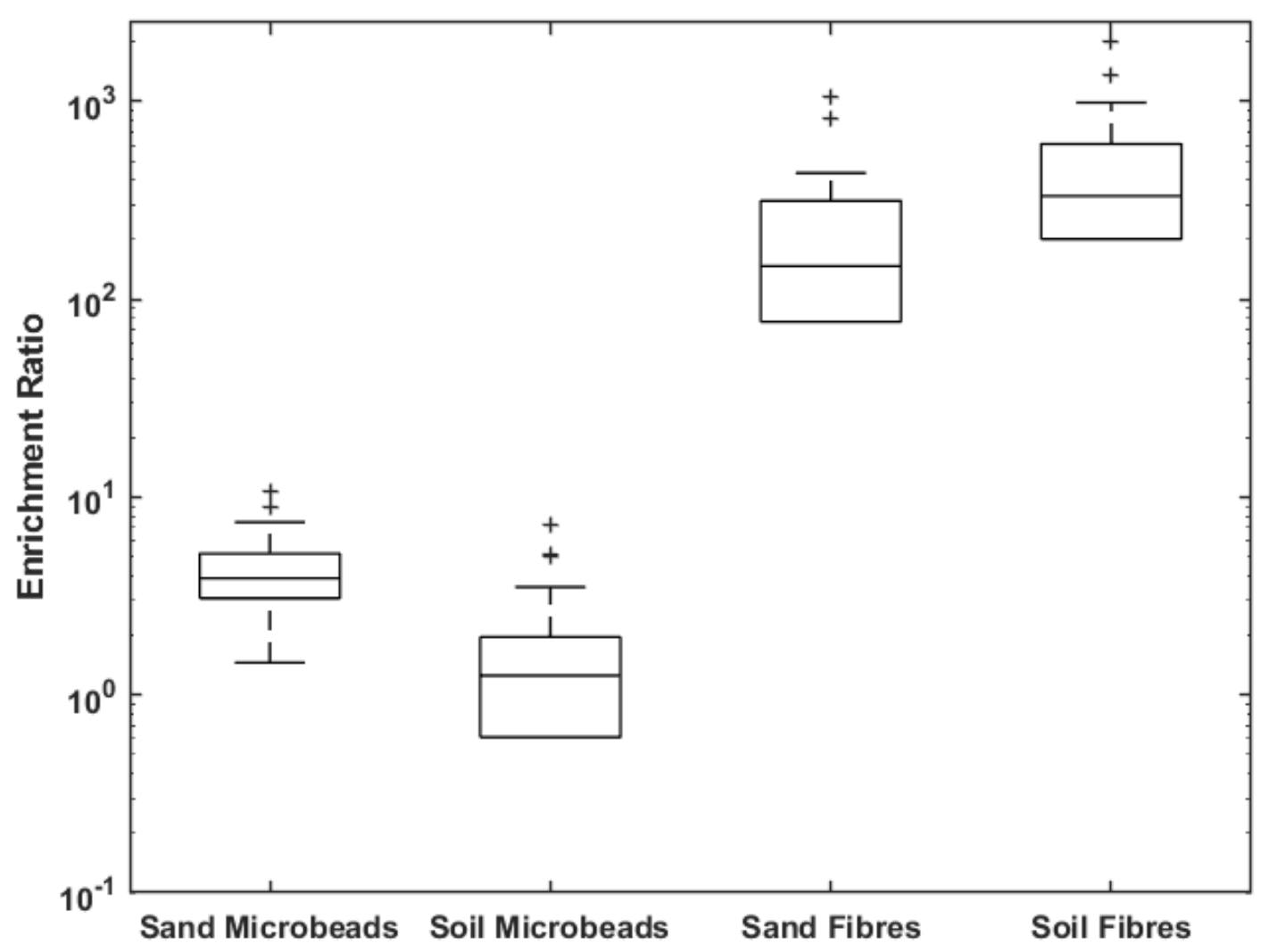

$304<$ Figure 3. Summary of the ratio of microplastic content in eroded material compared 305 to that in the original substrate. Box indicates median (centre line), $25^{\text {th }}$ and $75^{\text {th }}$ percentiles with outliers (>1.5 times inter-quartile range) indicated by '+' >> 
309 In order to determine the likelihood of microplastic particles being transported long

310 distances entrained material was trapped at differences downwind, up to 2 metres from

311 the downwind edge of each test bed. The enrichment ratios for each distance downwind

312 do not demonstrate any significant or systematic variability which suggests once

313 entrained into the airflow particles may be transported away from the source (Figure 4;

314 Table 5).

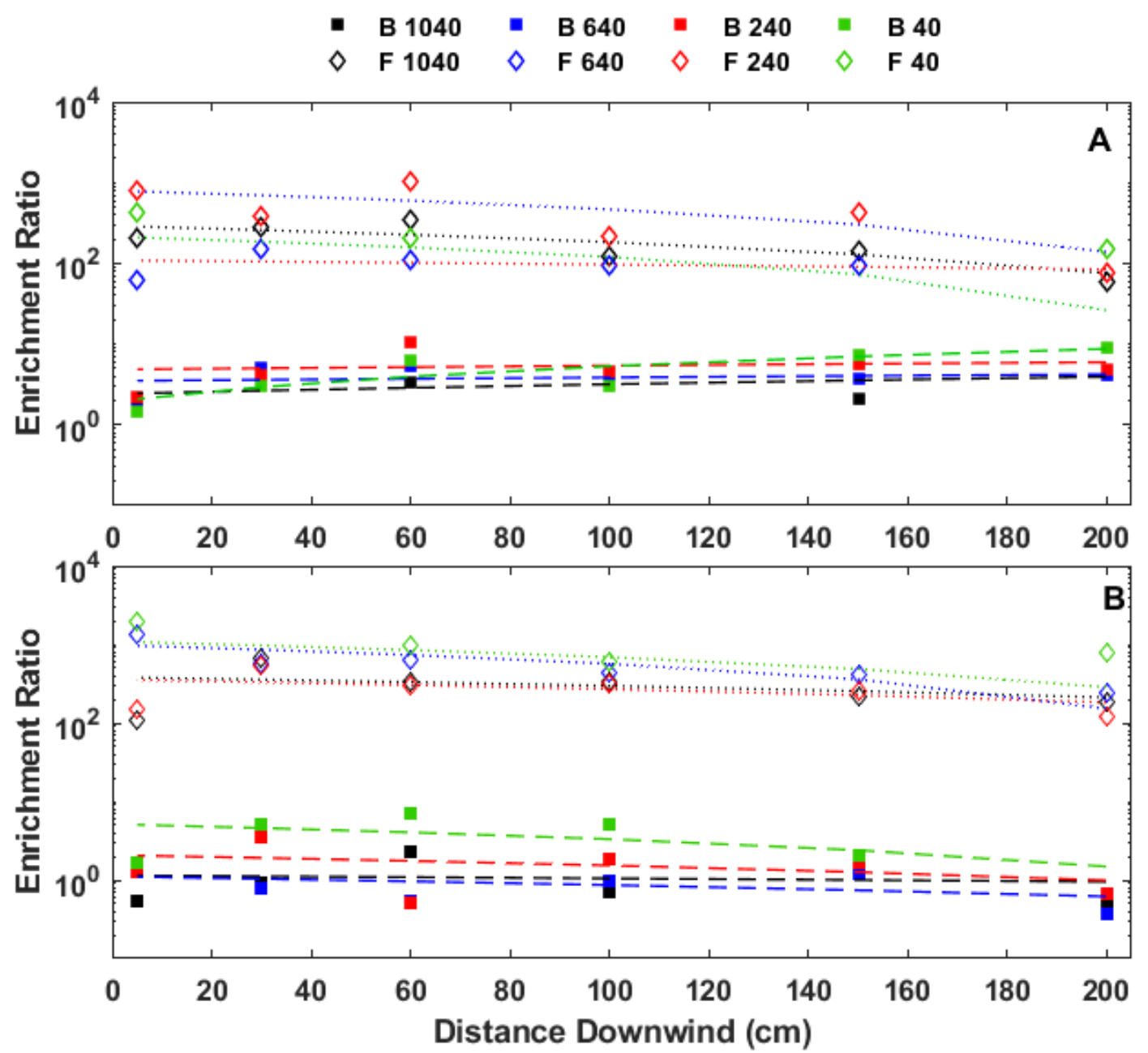

$317<<$ Figure 4: Change in microplastic enrichment ratio with distance downwind of the test

318 bed for (a) sand, and (b) soil. Lines indicate best-fit regression. $R^{2}$ values in Table 4. >> 


\section{Discussion}

323 Microplastics have recently been detected in the atmosphere, and in remote sites where

324 the most likely source of contamination is via atmospheric deposition (Zhang et al., 2020).

325 There has been very little research to date concerning the entrainment of microplastics

326 by wind at source, despite the fact that microplastic occurrence can be high in soils

327 susceptible to wind erosion (Rezaei et al., 2019). Similarly, very little is known about the

328 processes governing airborne microplastic transport (Horton \& Dixon, 2017). The data presented in this paper provide insights for a better understanding of the entrainment, transport and deposition of microplastics by wind when considered alongside previous research relating to the effects of particle density and shape on wind erosion and dust

332 emission.

The low density of plastics is expected to affect both their entrainment potential at source and settling velocity, which will determine long-distance transport potential and deposition rates. In this experiment, the density of microplastic particles $\left(1.2-1.38 \mathrm{~g} \mathrm{~cm}^{3}\right)$ is similar to that of organic soil components, which range from $1.0-1.5 \mathrm{~g} \mathrm{~cm}^{3}$ depending on the

338 degree of decomposition (Zenchelsky et al., 1976; Skopp, 2000). Wind-eroded material

339 from soils is often enriched in organic matter ( $E R=1$ to 10$)$ as compared with the 340 substrate from which it is entrained (Rühlmann et al., 2006; Webb et al., 2013; Iturri et 341 al., 2017). Whilst this enrichment varies on an event-by-event basis (Panebianco et al.,

342 2016), a common observation is that soil organic carbon enrichment is greater for soils 343 with a high sand content when compared to clay-rich soil (Webb et al., 2013; Panebianco 344 et al., 2016). This outcome is consistent with the experimental results presented here for 345 microbead entrainment where the ER is slightly higher for the sand as compared to the 346 soil. Microbead ERs observed here are similar in magnitude to ERs measured in the only 347 published field study of microplastic wind entrainment at source (Rezaei et al., 2019) (ER 
$348=0$ to 7.63 ), which also identifies a positive relationship between microplastic enrichment

349 and sand content, but does not provide information on particle shape. In contrast, the ER outcomes for fibre entrainment (Table 3 ) have a less clear association with substrate type where enrichment is generally, but not always, higher for soil rather than sand. Building on existing wind erosion studies of organic matter enrichment as an analogue, future research carried out in the laboratory and field should aim to quantify the relationship between microplastic enrichment and increasing wind speed, given the mobilisation of larger soil particle diameters with increased fluid drag.

A substantial unknown is the effect of low particle density on the vertical displacement of particles at the soil surface via saltation impact. Saltation is well-known as a process for driving not only the mobilization of surface particles by creep and dynamic saltation, but

360 also for the ejection of small and/or light particles higher in to the airstream where it is transported via suspension and may amplify long range transport (Iturri et al., 2017). The impact of particle density on the rate and nature of aeolian particle transport is poorly understood particularly for mixed substrates (Sherman, 2020). In a study to consider the

364 behaviour of snow particles, Gordon and McKenna Neuman (2011) compared the particle 365 splash dynamics of quartz sand (density $2.63 \mathrm{~g} \mathrm{~cm}^{3}$ ) and acrylic particles with a density of $1.21 \mathrm{~g} \mathrm{~cm}^{-3}$ and mean diameter of $192 \mathrm{um}$. They found the acrylic particles impacted 367 the bed surface at lower velocities and angles but caused the ejection of a greater number 368 of particles than the sand particles. The shape of the particles was argued to be important 369 due to its impact on particle packing and bed porosity. Owing to their low density, we 370 suggest that microplastic particles are unlikely to have sufficient kinetic energy to eject 371 mineral particles from the bed surface and thereby contribute to the development and 372 maintenance of the saltation cloud. This remains to be confirmed, however, as no 373 statistics exist on the number, launch angle and velocity components for microplastic 
374 particles splashed from a mixed bed surface as a consequence of particle impact.

375 Analogous to dust emission modelling, such information is required for estimating the sandblasting efficiency associated with release of microplastic particles to the atmosphere. Microplastic shape is also likely to influence the transfer of momentum from dynamic to static particles where compact (spherical) particles may be more effective than pliant (fibrous) particles. The relative proportion of mineral and microplastic particles would there be expected to affect overall aeolian transport.

382 With regards to the effect of particle shape, existing studies of microplastic deposition in both cities (Dris et al., 2016) and at remote mountain sites (Free et al., 2014; Allen et al., 2019) have found that fragments, films and fibres are more common than beads and 385 pellets. Results presented in this paper indicate that the entrainment of microbeads is 386 similar to, or slightly higher than, the entrainment of sand or soil, but that fibres are 387 considerably more likely to be entrained than either substrate. Although it was not possible explicitly to differentiate whether microplastic particles were entrained at lower wind speeds than mineral particles in the experiments reported here, Figure 2 suggests

390 that in the case of the sand bed this is likely to have been the case. Particle counts and 391 higher flux rates occurred at lower wind speeds for sand beds containing microplastics 392 than those without. This may be because the bed was loose and well-sorted and the low 393 density microplastic particles were more readily entrained than the mineral particles at 394 low wind speeds between intermittent and continuous saltation. Once the wind speed is 395 above the continuous saltation threshold the whole bed, including both sand and 396 microplastics, is mobilised. The dynamics of the soil beds are somewhat different to those 397 of the sand beds because the poorly-sorted soil substrate is more susceptible to 398 armouring as winnowing of fine particles takes place. Spherical microbeads are more 399 likely to be sieved down through the soil during the armouring process which would 
protect them from erosion whereas microplastic fibres may be less susceptible to sieving due to their shape and pliability. This may help to explain why fibres are more likely to be entrained but more research will be required to establish this. It is likely that fibres lying horizontally on the soil surface can be easily entrained but those caught in sediment interspaces and partially buried are likely to require higher shear stresses to be mobilized (Waldschläger and Schüttrumpf, 2019). Waldschläger and Schüttrumpf, (2019) suggest that within water the drag force is probably more important for the erosion of beads and the lift force more important for fibres and this may be the same for transport in air. The preferential entrainment of fibrous microplastics may also be due to their impact on soil porosity (de Souza Machado et al., 2018; Zhang et al., 2019).

Particle shape can be summarised by aspect ratio ( $\lambda$ - the ratio of particle length to width) and for natural mineral particles $\lambda$ is usually around 1.5 with a maximum of 5 , although for some mineralogies $\lambda$ of up to 10 can occur (Ginoux, 2003). For microplastics, $\lambda$ varies 414 substantially depending on type and origin. For the present study, $\lambda=1$ for the 415 microbeads, and for the fibres the modal $\lambda=5$ and mean $\lambda=8$ (range 1-40). Particles 416 with high $\lambda$ generally have an increased surface area to volume ratio, which for 417 microplastics descending in air, increases the opposing fluid drag relative to the 418 gravitational force. Neglecting particle interactions and Magnus effects (spin), the higher 419 drag associated with aspherical particles contributes to lower settling velocities, meaning 420 that once entrained the particles stay in the atmosphere for longer periods of time than 421 do spherical particles (Yang et al., 2003). Particle size modifies this effect to some extent 422 such that for a given shape, settling velocity is decreased less for small particles $(<5 \mu \mathrm{m})$ 423 than larger ones. Ginoux (2003) determined that for $100 \mu \mathrm{m}$ particles with $\lambda=10$, the 424 settling velocity was close to an order of magnitude slower than for a sphere of the same size. This has implications for the residence times of particles in the atmosphere, where 
$\lambda=10$ may result in a doubling of particle lifetime due to gravitational settling and

427 suggests that once microplastic fibres have been entrained they are more likely to travel longer distances than plastic microbeads.

Allen et al. (2019) estimated the distance over which microplastics deposited in a remote mountain catchment might have travelled (by assuming a settling velocity equivalent to 432 that for a $25 \mu \mathrm{m}$ dust particle) to be up to $95 \mathrm{~km}$. Using the same approach, and accounting for the size and density of the microbeads used here (particle diameter 250

$434 \mu \mathrm{m}$, particle density $1.2 \mathrm{~g} \mathrm{~cm}^{3}$ ), we estimate that dispersion up to $126 \mathrm{~km}$ from the source could occur for wind speeds averaging $7 \mathrm{~m} \mathrm{~s}^{-1}$. It is not yet possible to do the same 436 calculation for fibrous microplastics and given the likely influence of particle shape on 437 suspension and settling, we suggest that microplastic shape needs to be carefully parameterized to predict the transport distance for microplastic fibres and fragments.

\section{Conclusions}

442 Novel laboratory experiments have quantified, for the first time, the extent to which 443 microplastic particles are preferentially-transported compared to natural sediments. 444 Specifically, using sand and soil substrates containing either microplastic beads or fibres, 445 wind tunnel experiments were used to determine the impact of substrate and shape on 446 microplastic entrainment. At the concentrations tested here, results show that although 447 the inclusion of microplastics within a substrate was not found significantly to affect wind 448 erosion thresholds, overall particle flux for beds containing plastic particles was higher in 449 conditions above threshold. There is an enrichment of both types of microplastic particles 450 within the entrained particulate matter. This enrichment is of one to two orders of 451 magnitude for the microplastic fibres from both test bed substrates. The enrichment ratios 
452 of plastic particles do not demonstrate any significant or systematic variability with 453 distance down wind (over $2 \mathrm{~m}$ ) which suggests once entrained in to the air flow, particles 454 may be transported away from source.

455

456 The results reported here have provided first insights into the entrainment and transport 457 of microplastics from source substrates but questions remain as to the detailed particle458 scale processes by which microplastics are entrained in to the airflow. Considerably more 459 research into the roles of microplastic shape and density on their susceptibility to wind 460 erosion and long distance transport needs to be undertaken to effectively parameterize 461 models of atmospheric microplastic transport. Previous investigations into the wind 462 erosion and modelling of soil organic carbon enrichment and dispersal may provide a 463 useful starting point for future research in to airborne microplastics. 


\section{References}

465

466

467

468

469

470

471

472

473

474

475

476

477

478

479

480

481

482

483

484

485

486

487

488

489

490

491

492

Abbasi, S., Kechavarzi, B., Moore, F., Turner, A., Kelly, F.J., Dominguez, A.O., Jaafarzadeh, N. 2019. Distribution and potential health impacts of microplastics an dmicrorubbers in air and street dusts from Asaluyeh County, Iran. Environmental Pollution, 244, 153-164.

Allen, S., Allen,D., Phoenix, V.R., Le Roux, G., Durántez Jiménez, P., Simmoneau, A., Binet, S., Galop, D. 2019. Atmospheric transport and deposition of microplastics in a remote mountain catchment. Nature Geoscience, doi: 10.1038/s41561-019-03355

Ambrosini, R., Azzoni, R.S., Pillino, F., Diolaiuti, G., Franzetti, A., Parolini, M. 2019. First evidence of microplastic contamination in the supraglacial debris of an alpine glacier. Environmental Pollution 253, 197-301

Amec Foster Wheeler Environment \& Infrastructure UK Ltd. Intentionally added microplastics in products - final report for European Commission (DG Environment). Amec Foster Wheeler Environment \& Infrastructure UK Ltd. 2017.

Andrady, A.L. 2011. Microplastics in the marine environment. Marine Pollution Bulletin, 62, 1596-1605.

Arias-Andres, M., Kettner, M.T., Miki, T., Grossar, H.P. 2018. Microplastics: new substrates for heterotrophic activity contribute to altering organic matter cycles in aquatic ecosystems. Science of the Total Environment, 635, 1152-1159.

Barnes, D.K.A., Galgani, F., Thompson, R.C., Marlaz, M. 2009. Accumulation and fragmentation of plastic debris in global environments. Philosophical Transactions of the Royal Society B 364, 1985-1990

Beaumont, N.J., Aanesen, M., Austen, M.C., Borger, T., Clarke, J.R., Cole, M., Hooper, T., Lindeque, P.K., Pasco, C., Wyles, K.J. 2019. Global ecological, social and economic impacts of marine plastic. Marine Pollution Bulletin, 142, 189-195.

Bergmann, M., Mützel, M.S., Primpke, S., Tekman, M.B., Trachsel, J., Gerdts, G. 2019. White and wonderful? Microplastics prevail in snow from the Alps to the Arctic. Science Advances 5, eaax1157 
Boots, B., Russell, C.W. and Green, D.S. 2019. Effects of microplastics in soil ecosystems: above and below ground. Environmental Science and Technology, 53, 19, 11496-11506.

Boucher, J., Friot, D. 2017. Primary microplastics in the oceans: a global evaluation of sources, IUCN, Switerland.

Cai, L., Wang, J., Peng, J., Tan, Z., Zhan, Z., Tan, X., Chen, Q. 2017. Characteristic of microplastics in the atmospheric fallout from Dongguan city, Chine: preliminary research and first evidence. Environmental Science Pollution Research 24, 2492824935

Carbery, M., O'Connor, W., Thavamani, P. 2018. Trophic transfer of microplastics and mixed contaminants in the marine food web and implications for human health. Environment International, 115, 400-409.

Constant, M., Kerhervé, P., Mino-Vercellio-Verollet, M., Dumontier, M., Sànchez Vidal, A., Canals, M., Heissner, S. 2019. Beached microplastics in the Northwestern Mediterranean Sea, Marine Pollution Bulletin 142, 264-273

Davidson-Arnott, R.G.D., Bauer, O. 2009. Aeolian sediment transport on a beach: thresholds, intermittency, and high frequency variability. Geomorphology 105, 117126

Dehghani, S., Moore, F., Akhbarizadeh, R. 2017. Microplastic pollution in deposited urban dust, Tehran metropolis, Iran. Environmental Science and Pollution Research, 24, 20360-20371.

de Souza Machado, A.A., Lau, C.W., Till, J., Kloas, W., Lehmann, A., Becker, R., Rillig, M.C. 2018. Impacts of microplastics on the soil biophysical environment. Environmental Science and Technology, 52, 9656-9665.

Dris, R., Gasperi, C.J., Rocher, A.V., Saadi, B.M., Renault, N., Tassin, B. 2015. Microplastic contamination in an urban area: a case study in Greater Paris. Environmental Chemistry, 12, 592-599.

Dris, R., Gasperi, J., Saad, M., Mirande, C., Tassin, B. 2016. Synthetic fibers in atmospheric fallout: a source of microplastics in the environment? Marine Pollution Bulletin 104, 290-293 
Dris, R., Gasperi, J., Mirande, C., Mandin, C., Guerrouache, M., Langlois, V., Tassin, B. 2017. A first overview of textile fibers, including microplastics, in indoor and outdoor environments. Environmental Pollution, 221, 453-458.

Evangeliou, N., Grythe, H., Klimont, Z., Heyes, C., Eckhardt, C., Lopez-Aparicio, S., Stohl, A. 2020. Atmospheric transport is a major pathway of microplastics to remote regions. Nature Communications, 11, 3381.

Free, C.M., Jensen, O.P., Mason, S.A., Eriksen, M., Williamson, N.J., Boldgiv, B. 2014. High-levels of microplastic pollution in a large, remote, mountain lake. Marine Pollution Bulletin 85, 156-163

Folk, R.L., Ward, W.C. 1957. Brazos River bar: a study in the significance of grain size parameters. Journal of Sedimentary Petrology, 27, 3-26.

Fuller, S., Gautam, A. 2016. procedure for measuring microplastics using pressurized fluid extraction. Environmental Science and Technology 50, 5774-5780

Gasperi, J., Wright, S.L., Dris, R., Collard, F., Mandin, C., Guerrouache, M., Langlois, V., Kelly, F.J., Tassin, B. 2018. Microplastics in air: are we breathing it in? Current Opinion in Environmental Science and Health 1, 1-15

Ginoux, P. 2003. Effects of nonsphericity on mineral dust modelling. Journal of Geophysical Research 108

He, D., Luo, Y., Lu, S., Liu, M., Song, Y., Lei, L. 2018. Microplastics in soils: analytical methods, pollution characteristics and ecological risks. Trends in Analytical Chemistry, 109, 163-172.

Hidalgo-Ruz, V., Gutow, L., Thompson, R.C. Thiel, M. 2012. Microplastics in the marine environment: a review of the methods used for identification and quantification. Environmental Science and Technology, 46, 6, 3060-3075.

Horton, A., Dixon, S.J. 2017. Microplastics: an introduction to environmental transport processes. WIREs Water, 2018, 5, e1268.

Hu, D., Shen, M., Zhang, Y., Li, H., Zeng, G. 2019. Microplastics and nanoplastics: would they affect global biodiversity change? Environmental Science and Pollution Research, 26, 19997-20002. 
Iturri, L.A., Funk, R., Leue, M., Sommer, M., Buschiazzo, D.E. 2017. Wind sorting affects differently the organo-mineral composition of saltating and particulate materials in contrasting texture agricultural soils. Aeolian Research 28, 39-49

Jambeck, J.R., Geyer, R., Wilcox, C., Siegler, T.R., Perryman, M., Andrady, A., Narayan, R., Law, K.L. 2015. Plastic waste inputs from land into the ocean. Science, 347, 6223, 768-771.

Klein, M., Fischer, E.K. 2019. Microplastic abudance in atmospheric deposition within the Metropolitan area of Hamburg, Germany. Science of the Total Environment 685, 96103

Lehmann, A., Fitschen, K., Rillig, M. 2019. Abiotic and biotic factors influencing the effect of microplastic on soil aggregation. Soil Systems, 3, 21.

Li, B., McKenna Neuman, C., 2012. Boundary-layer turbulence characteristics during aeolian saltation. Geophysical Research Letters 39. DOI: 10.1029/2012GL052234

Li, C.R., Busquets, R., Campos, L.C. 2020. Assessment of microplastics in freshwater systems : a review. Science of the Total Environment, 707, art. no. 135578, doi : 10.1016.j.scitotenv.2019.135578.

Liu K., Wang, X., Fang, T., Xu, P., Zhu, L., Li, D. 2019. Source and potential risk assessment of suspended atmospheric microplastics in Shanghai. Science of the Total Environment, 675, 462-471.

Lwanga, E.H., Gertsen, H., Gooren, H., Peters, P., Salánki, T., can der Ploeg, M., Besseling, E., Koelmans, A.A., Geissen, V. 2016. Environmental Science and Technology, 50, 2685-2691.

Machado, A., Lau, C.W., Till, J., Kloas, W., Lehmann, A., Becker, R., Rillig, M.C. 2018. Impacts of microplastics on the soil biophysical environment. Environmental Science and Technology, 52, 9656-9665.

Mailhot, B., Morlat, S., Gardette, J.-L. 2000. Photooxidation of blends of polystyrene and poly_vinyl methyl ether): FTIR and AFM studies. Polymer, 41, 1981-1988.

McCormick, A., Hoellein, T.J., Mason, S.A., Schluep, J., Kelly, J.J. 2014. Microplastic is an abundant and distinct microbial habitat in an urban river. Environmental Science and Technology 48, 11863-11871 
McKenna Neuman, C., Nickling, W. G. 2000. Aeolian transport measurements: instruments and techniques. Proceedings from the CCRG Workshop on the Measurement and Simulation of Sediment Transport by Wind Trent University, Ontario

Nickling, W., McKenna Neuman, C., 1997. Wind tunnel evaluation of a wedge-shaped aeolian. Geomorphology 18, 333-345

North, E.J., Halden, R.U. 2013. Plastics and environmental health: the road ahead. Reviews on Environmental Health, 28, 1,

Ogungbemide, D., 2017. Wind tunnel simulation and modelling of dust emission from mine tailings (nepheline syenite), PhD Dissertation, Trent University.

PlasticsEurope, Plastics-The Facts 2019, An Analysis of European Plastics Production, Demand and Waste Data, PlasticsEurope, Brussels, Belgium 2019.

Panebianco, J.E., Mendez, M.J., Buschiazzo, D.E. 2016. PM10 emission, sandblasting efficiency and vertical entrainment during successive wind-erosion events: a windtunnel approach. Boundary-layer Meteorology 161, 335-353

Rezaei, M., Riksen, M.J.P.N., Sirjani, E., Sameni, A., Geissen, V. 2019. Wind erosion as a driver for transport of light density microplastics. Science of the Total Environment $669,273-281$

Roblin, B., Aherne, J. 2020. Moss as a biomonitor for the atmospheric deposition of anthropogenic microfibres. Science of the Total Environment, 715, 136973.

Rochman, C.M., Brookson, C., Bikker, J., Djuric, N., Earn, A., Bucci, K., Athey, S., Huntington, A., Mcllwraith, H., Munno, K., De Frond, H., Kolomijeca, A., Erdle, L., Grbic, J., Bayoumi, M., Borrelle, S.B., Wu, T., Santoro, S., Werbowski, L.M., Zhu, X., Giles, R.K., Hamilton, B.M., Thaysen, C., Kaura, A., Klasios, N., Ead, L., Kim, J., Sherlock, C., Ho, A., Hung, C. 2019. Rethinking microplastics as a diverse contaminant suite. Environmental Toxicology and Chemistry, 38, 4, 703-711.

RühImann, J., Körschens, M., Graefe, J. 2006. A new approach to calculate the particle density of soils considering properties of the soil organic matter and the mineral matrix. Geoderma 130, 272-283

Scheurer, M., Bigalke, M. 2018. Microplastics in Swiss floodplain soils. Environmental Science and Technology 52, 3591-3598 
613 Sharpley, A.N. 1985. The selective erosion of plant nutrients in runoff. Soil Science Society of America Journal 49, 1527-1534

615

Sherman, D.J. 2020. Understanding wind-blown sand: six vexations. Geomorphology, 366, 107193.

Skopp, J.M. 2000. Physical properties of primary particles. Handbook of Soil Science H. E. Summer, Ed. (CRC Press, Boco Raton, Florida, PP. A3-A17)

Song, Y.K., Hong, S.H., Jang, M., Han, G.M., Jung, S.W., Shim, W.J., 2017. Combined effects of UV exposure duration and mechanical abrasion on microplastic fragmentation by polymer type. Environmental Science and Technology 8, 43684376

Stanton, T., Matthew, J., Nathanail, P., MacNaughtan, W., Gomes, R.L. 2019. Freshwater and airborne textile fibre populations are dominated by 'natural', not microplastic fibres. Science of the Total Environment, 666, 377-389.

Tanaka, K., Takada, H. 2016. Microplastic fragments and microbeads in digestive tracts of planktivorous fish from urban coastal waters. Scientific Reports, 6, 34351.

von Moos, N., Burkhardt-Holm, P., Köhler, A. 2012. Uptake and effects of microplastics on cells and tissue of the Blue Mussel Mytilus edulis $L$. after an experimental exposure. Environmental Science and Technology, 46, 11327-11335.

Waldschläger, K., Lechthaler, S., Stauch, G., Schtüttrumpf, H. 2020. The way of microplastic through the environment - application of the source-pathway-receptor model (review). Science of the Total Environment, 713, 136584.

Waldschläger, K., Schtüttrumpf, H. 2020. Erosion behavior of different microplastic particles in comparison to natural sediments. Environmental Science and Technology, 53, 22, 13219-13227.

Wang, W.F., Ge, J., Yu, X.Y., Li, H. 2020. Environmental fate and impacts of microplastics in soil ecosystems: progress and perspective. Science of the Total Environment, 708, art. No. 134841, doiL 10.1016/j.scitotenv.2019.134841.

Webb, N.P., Strong, C.L., Chappell, A., Marx, S.K., McTainsh, G.H. 2013. Soil organic carbon enrichment of dust emissions: magnitude, mechanisms and its implications for the carbon cycle. Earth Surface Processes and Landforms 38, 1662-1671 
Wright, S.L, Thompson, R.C., Galloway, T.S. 2013. The physical impacts of microplastics on marine organisms: a review. Environmental Pollution 178, 483-492

Wright, S.L., Ulke, J., Font, A., Chan, K.L.A., Kelly, F.J. 2020. Atmospheric microplastic deposition in an urban environment and an evaluation of transport. Environment International, 136, 105411.

Wright, S.L., Kelly, F.J. 2017. Plastic and human health: a micro issue? Environmental Science and Technology, 51, 6634-6647.

Yang, W., Marshak, A., Kostinski, A.B., Várnai, T. 2003. Shape-induced gravitational sorting of Saharan dust during transatlantic voyage: evidence from CALIOP lidar depolarization measurements. Geophysical Research Letters 40, 3281-3286

Zenchelsky, S.T., Delany, A.C., Pickett, R.A. 1976. The organic component of wind-blown soil aerosol as a function of wind velocity. Soil Science 122, 129-132.

Yuan, J., Ma, J., Sun, Y., Zhou, T., Zhao, Y., Yu, F. 2020. Microbial degradation and other environmental aspects of microplastics/plastics. Science of the Total Environment, $715,136968$.

Zalasiewicz, J., Waters, C.N., Ivar do Sul, J.A., Corcoran, P.L., Barnosky, A.D., Cearreta, A., Edgeworth, M., Galuszka, A., Jeandel, C., Leinfelder, R., McNeill, J.R. Steffen, W., Summerhayes, C., Wagreich, M., Williams, M., Wolfe, A.P., Yonan, Y. 2016. The geological cycle of plastics and their use as a stratigraphic indicator of the Anthropocene. Anthropocene, 13, 4-17.

Zhang, K., Su, J., Ziong, X., Wu, X., Wu, C., Liu, J. 2016. Microplastic pollution of lakeshore sediments from remote lakes in Tibet plateau, China. Environnemental Pollution 219, 450-455

Zhang, G.S., Zhang, F.X., Li, X.T. 2019. Effects of polyester microfibers on soil physical properties: perception from a field and pot experiment. Science of the Total Environment, 670, 107.

Zhang, Y., Kang, S., Allen, S., Allen, D., Tanguang, G., Sillanpää, M. 2020. Atmospheric microplastics: a review on current status and perspectives. Earth-Science Reviews, 203, 103118.

Zhou, Q., Zhang, H., Fu, C., Zhou, Y., Dai, Z., Li, Y., Tu, C., Luo, Y. 2018. The distribution and morphology of microplastics in coastal soils adjacent to the Bohai Sea and the Yellow Sea. Geoderma, 322, 201-208. 


\section{Acknowledgments:}

677 The authors would like to thank Stacey Johnston and Taylor Brooks for their assistance 678 with the wind tunnel experiments. Funding: This research did not receive any specific 679 grant from external funding agencies in the public, commercial or not-for-profit sector. 680 Author contributions: All authors were involved in conceptualization and methodology. 681 PO'B and CMN analysed wind tunnel airflow and sediment transport data. JEB and AO 682 analysed microplastic and sediment samples. All authors interpreted data. All authors 683 wrote the manuscript. Competing interests: Authors declare no competing interests.

684 Data and materials availability: All data are available in the main text. 685 
686

687 688

Table 1: Folk and Ward (1957) statistics for substrate one (sand)

\begin{tabular}{l|lll}
\hline & Geometric $(\mu \mathrm{m})$ & Logarithmic $(\varnothing)$ & Description \\
\hline Mean & 254.2 & 1.976 & Medium sand \\
Sorting & 1.412 & 0.497 & Well sorted \\
Skewness & -0.129 & 0.129 & Fine skewed \\
Kurtosis & 1.099 & 1.099 & Mesokurtic \\
\hline
\end{tabular}

689

690

691

692

693

694 Table 2: Folk and Ward (1957) statistics for substrate two (soil)

695

\begin{tabular}{l|lll}
\hline & Geometric $(\mu \mathrm{m})$ & Logarithmic $(\varnothing)$ & Description \\
\hline Mean & 671.5 & 0.574 & Coarse sand \\
Sorting & 2.789 & 1.480 & Poorly sorted \\
Skewness & -0.025 & 0.025 & Symmetrical \\
Kurtosis & 0.832 & 0.832 & Platykurtic \\
\hline
\end{tabular}

696

697 
698 Table 3: Initial microplastic concentrations and average enrichment ratio (all distances) of 699 microplastics in wind-eroded material.

700

Average enrichment ratio (all distances)

\begin{tabular}{lllll} 
Substrate & $\begin{array}{l}\text { Concentration } \\
\left(\mathrm{mg} \mathrm{kg}^{-1} \mathrm{dw}\right)\end{array}$ & $\begin{array}{l}\text { Ratio of } \\
\text { microplastic:substrate }\end{array}$ & Microbead & Fibre \\
\hline Sand & 40 & $1: 25,000$ & 5.03 & 129.05 \\
& 240 & $1: 4167$ & 5.38 & 498.25 \\
& 640 & $1: 1563$ & 3.84 & 98.15 \\
& 1040 & $1: 962$ & 3.12 & 193.64 \\
Soil & & & & \\
& 40 & $1: 25,000$ & 3.49 & 726.40 \\
& 240 & $1: 4167$ & 1.59 & 278.14 \\
& 640 & $1: 1563$ & 0.89 & 606.67 \\
& 1040 & $1: 962$ & 1.06 & 305.40
\end{tabular}

701

702

703

704

705 
707 Table 4: Thresholds for intermittent and continuous saltation for each substrate/microplastic combination and $r^{2}$ regression coefficients for best-fit 708 relationships between enrichment ratio and distance downwind for different concentrations of microplastic (plotted in Figure 3 main text).

\begin{tabular}{|c|c|c|c|c|c|c|c|c|}
\hline \multirow[t]{2}{*}{$\begin{array}{l}\text { Substrate_microplastic } \\
\text { type }\end{array}$} & \multirow{2}{*}{$\begin{array}{l}\text { Microplastic } \\
\text { concentration } \\
\left(\mathrm{mg} \mathrm{kg}^{-1} \mathrm{dw}\right)\end{array}$} & \multicolumn{3}{|c|}{$\begin{array}{l}\text { Intermittent saltation threshold } \\
\left(\mathrm{m} \mathrm{s}^{-1}\right)\end{array}$} & \multicolumn{3}{|c|}{$\begin{array}{l}\text { Continuous saltation threshold } \\
\left(\mathrm{m} \mathrm{s}^{-1}\right)\end{array}$} & \multirow{2}{*}{$\begin{array}{l}r^{2} \text { relationship between } \\
\text { enrichment ratio and } \\
\text { distance downwind }\end{array}$} \\
\hline & & Run 1 & Run 2 & Run 3 & Run 1 & Run 2 & Run 3 & \\
\hline Sand (no microplastic) & 0 & 7.5 & 7.25 & 7.5 & 8 & 7.5 & 8 & - \\
\hline Sand_microbead & 1040 & 7.25 & 7.5 & 7.25 & 7.75 & 7.75 & 7.75 & 0.305 \\
\hline Sand_microbead & 640 & 7.5 & 7.25 & 7.25 & 8 & 8 & 7.75 & 0.038 \\
\hline Sand_microbead & 240 & 7.25 & 7.25 & 7.25 & 8 & 8 & 8 & 0.021 \\
\hline Sand_microbead & 40 & 7.5 & 7.5 & 7 & 8 & 8 & 8 & 0.754 \\
\hline Sand_fibre & 1040 & 7 & 7.25 & 7 & 7.75 & 8 & 7.75 & 0.556 \\
\hline Sand_fibre & 640 & 6.75 & 7 & 7 & 7.75 & 7.75 & 7.5 & 0.086 \\
\hline Sand_fibre & 240 & 7.5 & 7 & 7.25 & 8 & 7.75 & 7.75 & 0.438 \\
\hline Sand_fibre & 40 & 7.5 & 7.5 & 7.25 & 7.75 & 8 & 8 & 0.017 \\
\hline Soil (no microplastic) & 0 & 12 & 11 & 12 & 13 & 12.5 & 13.5 & - \\
\hline Soil_microbead & 1040 & 12.5 & 11 & 11.5 & 13 & 12.5 & 13 & 0.011 \\
\hline Soil_microbead & 640 & 13.5 & 13 & 11 & 14 & 13.5 & 12.5 & 0.197 \\
\hline Soil_microbead & 240 & 12 & 10.5 & 11 & 13.5 & 12 & 12 & 0.138 \\
\hline Soil_microbead & 40 & 12 & 11.5 & 11.5 & 13 & 12.5 & 13 & 0.255 \\
\hline Soil_fibre & 1040 & 12 & 10.5 & 10 & 13 & 12 & 13 & 0.110 \\
\hline Soil_fibre & 640 & 10 & 12 & 12 & 11.5 & 13.5 & 13.5 & 0.636 \\
\hline Soil_fibre & 240 & 12 & 12 & 11 & 13.5 & 13 & 12 & 0.195 \\
\hline Soil_fibre & 40 & 11 & 12 & 12 & 14 & 13 & 13 & 0.163 \\
\hline
\end{tabular}


712 Table 5: Microplastic enrichment for each substrate/microplastic combination, concentration

713 and distance.

714

\begin{tabular}{|c|c|c|c|c|c|}
\hline \multirow{2}{*}{$\begin{array}{l}\text { Microplastic } \\
\text { concentration } \\
\left(\mathrm{mg} \mathrm{kg}^{-1} \mathrm{dw}\right)\end{array}$} & \multirow{2}{*}{$\begin{array}{l}\text { Distance } \\
\text { downwind } \\
\text { (cm) }\end{array}$} & \multicolumn{4}{|c|}{ Enrichment ratio } \\
\hline & & Sand_microbead & Sand_fibre & Soil_microbead & Soil_fibre \\
\hline 1040 & 200 & 4.73 & 59.36 & 0.53 & 181.95 \\
\hline 1040 & 150 & 2.14 & 143.83 & 1.39 & 221.07 \\
\hline 1040 & 100 & 3.31 & 119.50 & 0.67 & 333.57 \\
\hline 1040 & 60 & 3.44 & 348.13 & 2.30 & 332.26 \\
\hline 1040 & 30 & 3.22 & 281.66 & 0.91 & 652.55 \\
\hline 1040 & 5 & 1.86 & 209.38 & 0.55 & 111.00 \\
\hline 640 & 200 & 4.10 & 76.98 & 0.37 & 241.75 \\
\hline 640 & 150 & 3.73 & 93.12 & 1.23 & 422.07 \\
\hline 640 & 100 & 3.34 & 92.51 & 0.95 & 431.65 \\
\hline 640 & 60 & 5.34 & 109.16 & 0.55 & 621.91 \\
\hline 640 & 30 & 5.02 & 153.46 & 0.77 & 574.40 \\
\hline 640 & 5 & 1.51 & 63.64 & 1.47 & 1348.23 \\
\hline 240 & 200 & 4.75 & 76.99 & 0.67 & 118.73 \\
\hline 240 & 150 & 5.79 & 435.57 & 1.67 & 254.31 \\
\hline 240 & 100 & 4.67 & 213.66 & 1.89 & 308.78 \\
\hline 240 & 60 & 10.71 & 1049.70 & 0.50 & 302.81 \\
\hline 240 & 30 & 4.06 & 393.94 & 3.52 & 531.05 \\
\hline 240 & 5 & 2.16 & 819.63 & 1.28 & 153.17 \\
\hline 40 & 200 & 8.94 & 150.34 & 0 & 778.83 \\
\hline 40 & 150 & 7.47 & 0 & 2.03 & 0 \\
\hline 40 & 100 & 3.08 & 0 & 5.02 & 598.38 \\
\hline 40 & 60 & 6.17 & 204.26 & 7.19 & 987.48 \\
\hline 40 & 30 & 30.08 & 0 & 5.09 & 0 \\
\hline 40 & 5 & 1.46 & 419.72 & 1.63 & 1993.68 \\
\hline
\end{tabular}

